\title{
Isolation and Microscopic Study of Leaf Spot of Chromolaena odorata (Siam Weed) caused by Phytophthora spp. from Tripura
}

\author{
Durga Prasad Awasthi ${ }^{1}$ and Sumen Kapali ${ }^{2 *}$ \\ ${ }^{1}$ Department of Plant Pathology, College of Agriculture, Tripura, India \\ ${ }^{2}$ Vocational Education Teacher (Agriculture), SIBIN Group, Kamalghat Higher Secondary \\ School, India \\ *Corresponding author
}

\begin{abstract}
A B S T R A C T
Keywords

Asteraceae,

Sporangia,

Sporangiophores,

Monochasium,

Dichasium

Article Info

Accepted:

17 March 2019

Available Online:

10 April 2019

To explore bio-control options available for management of Siam weed, a survey was conducted during the year 2017-18 and 2018-19 in different districts of Tripura, India. During survey, symptoms of leaf blight were observed on leaves of Siam weed. Fungi isolated from infected sample on PDA media shows slow growth covering whole petri plate within 10 days. During incubation period fungal sporulation increases with increase in growth period. Identification of suspected causal agent was Phytophthora which was confirmed based on the morphology. Culture colonies of Phytophthora produce coenocytic hyphae, unbranched sporangiophores, ovoid or subglobose to globose hyphal swellings with an average diameter of $18.6 \pm 6.5 \mu \mathrm{m}$. Pathogenicity tests were carried out for further confirmation. Based on morphological features, the fungus on Siam weed was identified as Phytophthora spp. Based on available reviews, this is the first incidence of report of Phytophthora spp. from Tripura under the family Asteraceae, causing Leaf blight on Siam weed.
\end{abstract}

\section{Introduction}

Siam weed (Chromolaena odorata \& $C$. squalida), looks similar to Blue top or Billy goat weed (Ageratum spp.), mature plants have a growth habit similar to Lantana (Lantana camara).

Chromolaena odorata has become one of the worst terrestrial invasive plants in the humid tropics and northeastern India (Waterhouse, 1994) It contains very high nitrate levels and may also cause skin complaints and asthma in allergy-prone people (Prasad et al., 2005, Koutika et al., 2010).

To explore bio-control options available for its management a survey was conducted during the year 2017-18 and 2018-19 in different districts of Tripura. The present study revealed incidence and occurrence of Phytophthora species causing leaf spot of Siam weed under Agro-climatic condition of Tripura. 


\section{Materials and Methods}

During the year 2017-18 and 2018-19, a routine survey on plants of Siam weed was conducted in the different Districts of Tripura, India namely, Gomati, Siphahijala, Khowai, west, South, Dhalai, Unokoti, and North Tripura. In vivo observation of disease symptoms were carried out, time of occurrence of disease, plant part affected and development process was recorded at regular interval. Samples were brought into the laboratory and compared with standard Disease Atlas and Books. Pathogen concern is isolated aseptically in Potato Dextrose Agar (PDA) slants. Before isolation small bits from the diseased plant parts were cut and washed in running tap water followed by washing in distilled water. The washed samples were then dipped in $0.1 \% \quad \mathrm{HgCl}_{2}$ (Mercuric Chloride) solution for 30 to 45 seconds for surface sterilization and then washed in sterile distilled water. The PDA slants were then incubated at $28 \pm 1{ }^{\circ} \mathrm{C}$ in B.O.D. incubator for 14 days. Further sub culturing was carried out by taking $6 \mathrm{~mm}$ discs. The isolated fungus was inoculated into healthy plants grown in pots for confirmation of Koch postulates. Leaves sample and isolated fungi were mounted in Canada balsam and stained with cotton blue. For taxonomic identification, the morphology of obtained isolates was examined at $10 \mathrm{X}, 40 \mathrm{X}$ and $100 \mathrm{X}$ magnifications. Colony growth patterns were examined at incubating the pathogen for one week at $20^{\circ} \mathrm{C}$ in the dark on agar media.

\section{Results and Discussion}

In vivo observation of affected leaves initially show small dark spots which enlarge rapidly and turn purplish brown at the margins and tips of the leaf (Fig. 1). As the disease progresses, the lesions (mostly along the leaf margin) continue to expand and frequently coalesce. The boundary between the healthy and diseased tissues is usually indistinct and smooth. The morphology of Phytophthora spp. was examined at $10 \mathrm{X}, 40 \mathrm{X}$ and $100 \mathrm{X}$ magnifications using a light microscope, the result revealed that the sexual morph of this fungus was absent. Culture colonies of Phytophthora isolates on the PDA medium (Fig. 2) shows creamy white, wooly slow growth fungi. At initial level Primary hyphae grows slowly often branching in a mono- or dichasium with the mother hypha ending in a short protruding tip largely submerged with limited felty aerial mycelium ( Fig. 3 and 4). Initially, Sporangia were not observed on solid agar but are produced abundantly after 24 hours in the same agar plate, borne terminally on unbranched sporangiophores, non-caducous, and papillate (Fig. 5 and 6), ovoid or subglobose to globose and irregular hyphal swellings (Fig. 7 and 8 ) with an average diameter of $18.6 \pm 6.5 \mu \mathrm{m}$ produced abundantly. Chlamydospores were not observed. The morphological and microscopic study confirms the asexual morph of Phytophthora spp as causal organisum of leaf spot of Siam weed. The pathogen is readily identified as an asexual morph of the genus Phytophthora which are according to the findings of Andre and Sendall, 2001; Goheen et al., 2007; Latham et al., 2015). In future course of study molecular sequence analyses need to be taken up for further confirmation.

In the pathogenicity test, inoculated leaves developed leaf spots symptoms 10 days after inoculation, where the control leaves remained healthy. The fungus present on the inoculated leaves was morphologically identical to that originally observed on disease plants.

Although no prominent report so far has been recorded about the incidence of Phytophthora in Siam weed from Tripura. The Siam weed belongs to the family Asteraceae it includes Aster, Dahlia, Marigold, Safflower, 
Sunflower, Stevia, Znnia etc. Phytophthora Susceptible hosts includes the members of the Asteraceae, Ranunculaceae, Lamiaceae, Rhamnaceae, Phrymaceae, Rosaceae, and Verbenaceae plant families (Latham et al.,
2015). Chromolaena odorata belongs to the Asteraceae (Compositae), a large, welldefined and highly evolved family (Toelken, 1983; Bremer, 1994; APG II, 2003) (Table 1).

Table.1 In vivo observation of disease symptoms, time of occurrence of disease, plant part affected and pathogen stages recorded

\begin{tabular}{|c|c|c|c|}
\hline Sl.No. & Plant Part affected & Visibility of the symptoms & Time of Occurrence \\
\hline 1 & Leaves & Usually visible to the naked eye & June-February \\
\hline 2 & Stems (above ground) & Usually visible to the naked eye & \\
\hline
\end{tabular}

Fig.1 1.Phytophthora infected Siam Weed, 2. Culture of Phytophthora on PDA, 3. 4., Hyphae initially with slow growth branching with the hypha ending in a short protruding tip (10 X), 5., 6., Sporangia terminally on unbranched sporangiophores, non-caducous, and non-papillate (40 X), 7., 8., Sporangia ovoid or subglobose to globose or Non papilate (100 X)

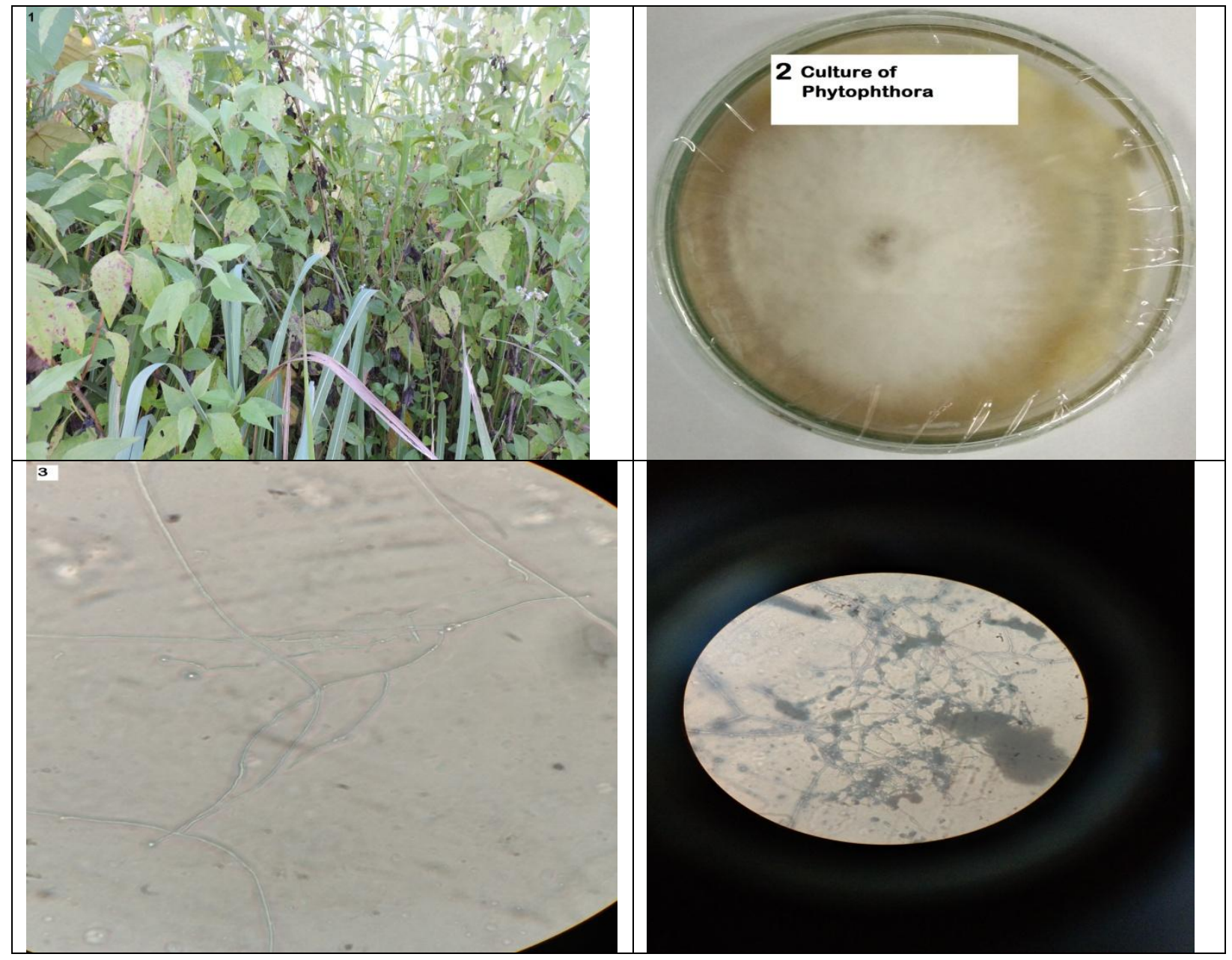




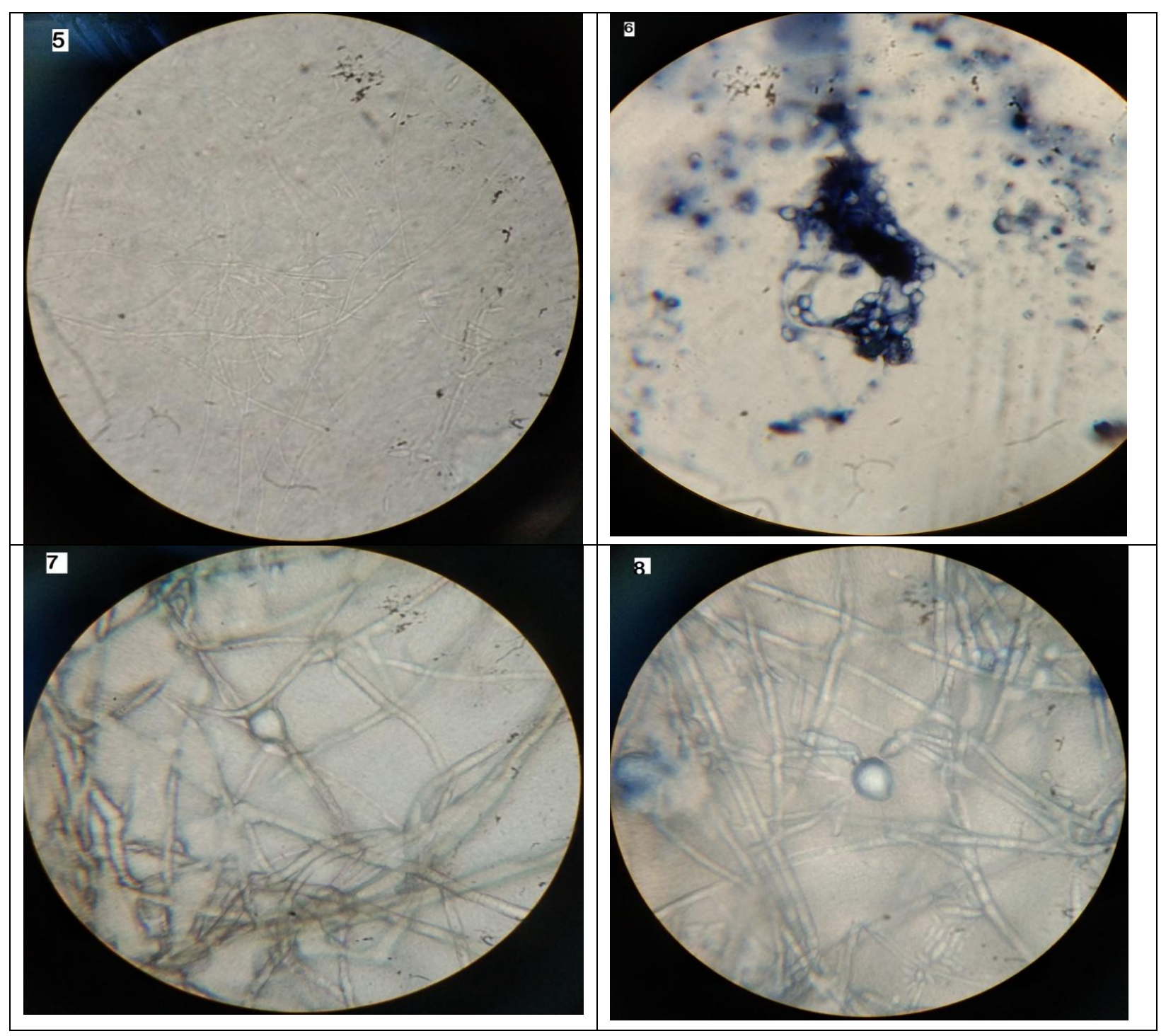

Siam weed mainly of the tropics and subtropics, many of the countries in which it is a problem do not have the resources to implement comprehensive control programs using conventional methods. Consequently, biological control has become an important management tool (Boller et al., 2006). Research into the potential of biological control for C. odorata through Phytophthora presumably used as a biological agent to keep it under control.

In conclusion, the pathogen produced purplish-brown, blackish water soaked lesions seen on margin of the leaves. Sporulation in Phytophthora cultures provides important clues for identification. Chlamydospores were not observed. Sporangia are borne terminally on unbranched sporangiophores, noncaducous, papillate, ovoid, subglobose to globose with irregular hyphal swellings having average diameter of $18.6 \pm 6.5 \mu \mathrm{m}$. This confirmed the fungi as asexual morph of Phytophthora spp. having high potential for exploring it as bio-control agent against Siam weed management.

\section{References}

Boller, E. F., van Lanteren, J. C. and Delucchi, V. (2006). International Organization for Biological Control of 
Noxious Animals and Plants. History of the First 50 Years (1956-2006). IOBC, Zurich, Switzerland, Pp. 275.

Bremer, K. (1994). Asteraceae - Cladistics and Classification. Portland, OR: Timber Press. APG II (2003). An update of the Angiosperm Phylogeny Group classification for the orders and families of flowering plants: APG II. Botanical Journal of the Linnean Society, 141, 399-436.

Drenth, A., and Sendall, B., (2001). Practical guide to detection and identification of Phytophthora, CRC for Tropical Plant Protection Brisbane Australia.

Goheen, E. M. and Frankel, S. J., (2007). Phytophthoras in Forests and Natural Ecosystems, Proceedings of the Fourth Meeting of the International Union of Forest Research Organizations (IUFRO) Working Party, Monterey, California.
Chromolaena odorata in different ecosystems: weed or fallow plant. Applied Ecology and Environmental Research. 8(2): 131-142.

Latham, R., Blomquist, S., Swiecki,C.L. and Bernhardt, E. (2015). Phytophthora tentaculata. Forest Phytophthoras 5(1).

Prasad, Narayana, S., Jayakumar, K., Srikanth, K.G., (2005). Phytochemical Analysis of Toxic Plant Chromolaena odorata (Eupatorium odoratum). Journal of the Indian Society of Toxicology, 1:1.

Toelken, H. R. (1983). Compositae. In Flowering Plants in Australia, ed. B. D. Morley and H. R. Toelken. Adelaide, Australia: Rigby, Pp. 300-314.

Waterhouse, D. F. (1994b). Biological Control of Weeds: Southeast Asian Prospects. ACIAR Monograph, 26: 1302.

Koutika, L., Rainey, S. H.J. (2010).

\section{How to cite this article:}

Durga Prasad Awasthi and Sumen Kapali. 2019. Isolation and Microscopic Study of Leaf Spot of Chromolaena odorata (Siam Weed) caused by Phytophthora spp. from Tripura. Int.J.Curr.Microbiol.App.Sci. 8(04): 2323-2327. doi: https://doi.org/10.20546/ijcmas.2019.804.271 